\title{
Mientras agoniza: Examen crítico del modelo procesal de instancia única en materia laboral de la Provincia de Buenos Aires
}

\author{
As It Lay Dying: Critical Exam of the Unique Court Model for Labor Matters \\ in the Province of Buenos Aires
}

\author{
Luciano D. Laise ${ }^{1}$ \\ ORCID: 0000-0003-4249-5948 \\ Juan Sebastián Bohorquez-Artunduaga ${ }^{2}$ \\ ORCID: 0000-0002-0686-0031 \\ ${ }^{1}$ Consejo Nacional de Investigaciones Científicas y Técnicas (CONICET), Argentina. \\ ${ }^{2}$ Universidad de La Sabana, Colombia. \\ Correspondencia: lucianolaise@conicet.gov.ar; juanboar@unisabana.edu.co
}

Resumen: Las garantías procesales mínimas incluyen la posibilidad de una doble instancia judicial, tal como lo ha reconocido el artículo $8^{\circ}$ inciso $2^{\circ}$ literal h de la Convención Americana sobre Derechos Humanos. A pesar de que esa disposición convencional se refiere exclusivamente a procesos de índole criminal o penal, la Corte Interamericana de Derechos Humanos ha considerado que tal garantía procesal se ha de extender a pleitos de naturaleza fiscal, administrativa, civil y laboral. Este artículo sostendrá que si bien el régimen procesal de instancia única en materia laboral de la Provincia de Buenos Aires (Argentina) ya ha sido derogado, lo cierto es que este persiste en un estado de agonía, porque todavía no se han integrado las Cámaras de Apelación del Trabajo. De hecho, la Suprema Corte de Justicia de la Provincia de Buenos Aires ratifica su negativa a concretar por ella misma el derecho al recurso hasta que se pongan en funcionamiento esos tribunales de apelación. La situación descrita no solo resultaría insuficientemente adecuada a los estándares procesales a nivel interamericano, sino que también implicaría un estado de indefensión para un sujeto de especial protección constitucional: el trabajador.

Palabras clave: sujetos de especial protección; vulnerabilidad; principio protectorio; trabajador; apelación.

\begin{abstract}
Procedural guarantees include the possibility of reviewing the sentence by a higher court, as recognized in Article 8.2.h of the American Convention of Human Rights. Although that provision refers solely to criminal judgments, the Inter-American Court of Human Rights holds that the former procedural guarantee applies also to tax, administrative, civil and labor law. This article will maintain that even the unique court model was left behind, judges has not been provided in the Chambers of Appeals of Labor. In fact, there is not a single change in the actual enforcement of the right to appeal. Even more, Buenos Aires' State Supreme Court still holds its same positions and, thus, it rejects to enforce to that right by itself. That does not fit in procedural standards of the regional system and, besides, it entails a lack of defense for a subject of preferent constitutional protection: the worker.
\end{abstract}

Keywords: subject of preferent constitutional protection; vulnerability; labor protection principle; worker; appeal. 


\section{Introducción: un cuestionable y polémico control de convencionalidad}

La Suprema Corte de Justicia de la Provincia de Buenos Aires —en adelante: SCBA— ha resuelto, en R. E. M. contra Colegio de Kinesiólogos de la Provincia de Buenos Aires s/ pretensión anulatoria — en adelante: "REM c/ Colegio de Kinesiólogos" —, que el régimen procesal bonaerense que establece la única instancia en materia laboral, se adecúa a lo dispuesto por el artículo $8^{\circ}$ inciso $2^{\circ}$ literal h de la Convención Americana de Derechos Humanos —en adelante $\mathrm{CADH}$ - ya que tal disposición convencional se aplicaría exclusivamente en materia penal (SCBA, "REM c/ Colegio de Kinesiólogos”, 2011, pp. 8$11)^{1}$. De hecho, el máximo tribunal bonaerense ha sostenido que la Corte Interamericana de Derechos Humanos — en adelante: Corte IDH_ “no se ha expedido en forma concreta y clara en lo que tiene que ver con la doble instancia en los pleitos no criminales" (SCBA, "REM c/Colegio de Kinesiólogos”, 2011, p. 46).

Aún más, la SCBA ha descartado expresamente la interpretación de la Corte IDH en su Opinión Consultiva $\mathrm{N}^{\circ} 11 / 90$ "Excepciones al agotamiento de los recursos internos (arts. 46.1, 46.2 a y 46.2.b de la CADH)" — en adelante: “Opinión Consultiva $\mathrm{N}^{\circ}$ 11/90" — sobre el alcance de la garantía del debido proceso (SCBA, "REM c/ Colegio de Kinesiólogos", 2011, Pág. 73). De esta manera, el máximo órgano judicial del Poder Judicial de la Provincia de Buenos Aires hace una referencia genérica a la jurisprudencia interamericana, en la que mantiene que esta no ha prescrito explícitamente el deber de instituir una doble instancia para procesos extrapenales.

En efecto, a pesar de la incorporación en el bloque de constitucional, en el año 1994, de los artículos 8 apartado 2 inciso h de la CADH y el 14 inciso 5 del Pacto Internacional de Derechos Civiles y Políticos, la obligatoriedad de la doble instancia, incluso en cuestiones no penales, no habría quedado establecida en Argentina (SCBA, Lozano, J. C. c/ Lavagnino Metalmecánica y otro s/ Despido, 2015, p. 17). Sin embargo, lo cierto es que la Corte IDH sí mantuvo el deber de extender a otros órdenes — p. e., fiscal, laboral, administrativo o civil— los estándares de las garantías procesales dispuestos para la materia penal. Así lo ha hecho en los casos "Panel Blanca” (Paniagua Morales y otros) vs. Guatemala.” (1998), "Tribunal

\footnotetext{
${ }^{1}$ El primer caso de la jurisprudencia bonaerense en que se ha desarrollado más explícitamente una adecuación del régimen de instancia única con la Convención Americana de Derechos Humanos ha sido en SCBA "REM c/ Colegio de Kinesiólogos", 2011. Sin embargo, eso ha sido ratificado y profundizado en precedentes más recientes como SCBA “Lozano, J. C. c/ Lavagnino Metalmecánica y otro s/ Despido”, 2015, tal como se verá más adelante. Asimismo, cabe aclarar que en diciembre de 2019 la SCBA reiteró su rechazo a disponer una doble instancia laboral a través de la Resolución No 3199/19; salvo en lo que respecta a determinadas cuestiones vinculadas con enfermedades y accidentes laborales.
} 
Constitucional" (Aguirre Roca, Rey Ferry y Revoredo Marsano) vs. Perú.” (2001a); "Baena Ricardo y otros vs. Panamá” (2001b) "Ivcher Bronstein vs. Perú." (2001c).

De hecho, en Ivcher Bronstein vs. Perú. — en adelante: "Bronstein" — la Corte IDH ha establecido que, a pesar de que el artículo 8.2. de la CADH "no especifica garantías mínimas en materias que conciernen a la determinación de los derechos y obligaciones de orden civil, laboral, fiscal o de cualquier otro carácter, las garantías mínimas establecidas en el numeral 2 del mismo precepto se aplican también a esos órdenes y, por ende, en éstos el individuo tiene derecho al debido proceso en los términos reconocidos para la materia penal" (Corte IDH, "Bronstein”, 2001c, párr. 103).

Situados en este contexto de ideas, hay un punto que resulta especialmente significativo sobre la extensión del "derecho al recurso" a la doble instancia judicial. Más en concreto, si el trabajador es considerado un "sujeto de especial protección constitucional", tal como lo ha establecido la Corte Suprema de Justicia de la Nación, — en adelante SCJN—este podría resultar desprotegido si no se le asegurase un derecho a apelar en el marco de una segunda instancia ordinaria (CSJN, Vizzoti, Carlos c/ AMSA S.A. s/ Despido, 2004a, consid. 10; CSJN, Aquino, Isacio c/ Cargo Servicios Industriales S.A. s/ Accidentes ley 9688, 2004b, consid. 1).

Cabe aclarar que si bien esta problemática de la doble instancia parece haber sido solucionada por la reforma al procedimiento laboral en la Provincia de Buenos Aires (Ley $\mathrm{N}^{\mathrm{o}}$ 15.057/18), lo cierto es que no se han constituido las Cámaras de Apelación del Trabajo que estableció el art. 2 de la citada ley provincial. De hecho, a la fecha en que se ha finalizado este trabajo, ni siquiera se ha convocado a concurso para proveer tales cargos judiciales ${ }^{2}$. De manera que persiste la carencia de una segunda instancia laboral en la Provincia de Buenos Aires. Además, resulta preciso subrayar que la propia SCBA ha dejado en claro que la doble instancia laboral solo se tornará operativa cuando los tribunales de impugnación en materia laboral empiecen a funcionar (SCBA, Resolución No 3199/19).

En consecuencia, la problemática que aborda este trabajo no ha perdido su vigencia. Y, por otra parte, esta investigación también podría echar luz sobre los regímenes procesales

\footnotetext{
${ }^{2}$ Una consulta al sitio web del Consejo de la Magistratura de la Provincia de Buenos Aires, en septiembre de 2020, revela que no existe novedad sobre alguna clase de convocatoria para cubrir los cargos de jueces en la Cámara de Apelación del Trabajo. Además, ya que la última novedad es que en junio se han sustanciado los exámenes escritos de concursos convocados a mediados de 2019, todo indica que falta un buen tramo para que se constituya la segunda instancia en material laboral en la jurisdicción bonaerense. Muy especialmente porque no se trata tan solo de reemplazar cargos por jubilaciones o renuncias que tienen sus propias imputaciones presupuestarias, sino que se torna necesario reformular la entera estructura organizativa de la justicia laboral para crear los cargos de jueces, secretarios, prosecretarios y todo el soporte administrativo en que descansará la nueva justicia laboral bonaerense. Ver más en http://www.cmagistratura.gba.gov.ar/web/index.php/concursos
} 
de instancia única, tal como sucede en la provincia de Jujuy y de La Rioja (Fenochietto, 2003, p. 300), ya que en ellos solo se establece un derecho a la doble instancia en materia penal. El problema que se tratará en las próximas páginas resulta ser una cuestión de suma relevancia, porque la institución de una instancia única frustraría la posibilidad de debatir con amplitud tanto la valoración de las pruebas como el derecho aplicable, lo cual resultaría especialmente gravoso para un sujeto que debiera ser protegido de una manera más intensa que lo habitual. Por ello, la tesis que defenderá este artículo es que el régimen procesal que estableció una instancia única en material laboral resulta particularmente lesivo para quien se encuentra en un particular estado de indefensión: el trabajador.

La presente contribución se estructurará con (i) una descripción de la jurisprudencia interamericana - tanto consultiva como contenciosa - en materia de derecho a una doble instancia en materia extrapenal. (ii) Se contrastará esa jurisprudencia interamericana con los argumentos esgrimidos en los precedentes de la SCBA que rechazan aplicar el derecho a una doble instancia a pleitos de naturaleza laboral. (iii) Se examinará la consistencia del rechazo de la SCBA a una doble instancia judicial no solo con relación a la jurisprudencia de la Corte IDH sobre el llamado "derecho al recurso", sino también a la luz del concepto de sujeto de preferente protección constitucional que la CSJN atribuye a los trabajadores. Además, se evaluará el grado de coherencia que guardan las prácticas interpretativas de la SCBA y su propia pretensión de adecuarse a las interpretaciones de los derechos fundamentales que realiza la Corte IDH. Por último, (iv) se finalizará con un apartado en el cual se recapitularán las principales conclusiones de esta investigación.

\section{El derecho a la doble instancia en materia laboral: un abordaje desde la jurisprudencia interamericana}

El derecho al recurso en materia no penal ha sido reconocido por la Corte IDH a partir de la citada Opinión Consultiva $\mathrm{N}^{\circ} 11 / 90^{3}$. En esa oportunidad se mantuvo que tal derecho al recurso integra las "garantías mínimas" del proceso, no solo en materia penal, sino también en el orden civil, laboral, fiscal o cualquier otro (Corte IDH, Opinión Consultiva $\mathrm{N}^{\circ}$ 11/90, 1990, párr. 28). Es justo reconocer que la referida Opinión Consultiva № $11 / 90$ respondía a preguntas que tenían por objeto analizar si se aplica el requisito de agotar recursos internos para acceder a la jurisdicción de la Corte IDH en el supuesto de personas indigentes. Sin embargo, el tribunal interamericano se ocupó de brindar una respuesta más amplia a lo

\footnotetext{
${ }^{3}$ Kielmanovich asume que la jurisprudencia y la CADH establece un derecho a la doble instancia en materia penal, pero afirma que no comprende las causas que llevaron a tal reconocimiento (2006).
} 
estrictamente solicitado y, por ende, se detuvo a determinar el significado de esas "garantías procesales mínimas" que reconoce el Artículo 8.2 de la CADH.

Ahora bien, ¿qué significa el concepto de derecho al recurso? Según el entendimiento de la Corte IDH tal derecho hace referencia a la idea de que todo medio de impugnación ha de ser eficaz y permitir controlar las cuestiones fácticas, probatorias y jurídicas (Herrera Ulloa vs. Costa Rica, 2007, párr. 137). De esta manera, el derecho al recurso es considerado como un elemento imprescindible del derecho fundamental al debido proceso. Aún más, el derecho al debido proceso sería indivisible y sus garantías se han de aplicar a todo proceso independiente del objeto de este, ya que las exigencias mínimas se instituyen en favor del justiciable, no del juez o tribunal. Por ello, el derecho al recurso sería exigible en materia extrapenal (Valenzuela, 2013, pp. 713 y 728).

Lo dicho anteriormente ha sido reiterado por la Corte IDH en el caso "Panel Blanca" (Paniagua Morales y otros) vs. Guatemala —en adelante: "Panel Blanca" —, el cual ratifica lo manifestado en la Opinión Consultiva $\mathrm{N}^{\circ} 11 / 90$ sobre el sentido que cabe atribuir al Artículo 8.2. de la CADH (Corte IDH, "Panel Blanca", 1998, párr. 149). Con todo, vale reconocer que tal es un caso de naturaleza penal. Otra consideración merece el caso "Tribunal Constitucional” (Aguirre Roca, Rey Ferry y Revoredo Marsano) vs. Perú —en adelante: "Tribunal Constitucional" - , porque en tal pleito no se discutían cuestiones penales, sino un proceso de remoción de magistrados del Tribunal Constitucional de Perú y, sobre todo, porque se resolvió expresamente que tales magistrados contaban entre las "garantías procesales mínimas" - Artículo 8.2. de la $\mathrm{CADH}$ — con mecanismos de impugnación como aquellos que caben para una acusación penal, reiterando pues lo dictaminado en la Opinión Consultiva 11/90 (Corte IDH, “Tribunal Constitucional”, 2001, párr. 69-70). Cabría hacer referencia al caso Baena Ricardo y otros vs. Panamá — en adelante: "Baena” —. En esa sentencia se indicó que:

\footnotetext{
"la Corte observa que el elenco de garantías mínimas establecido en el numeral 2 del artículo 8 de la Convención se aplica a los órdenes mencionados en el numeral 1 del mismo artículo, o sea, a la determinación de derechos y obligaciones de orden civil, laboral, fiscal o de cualquier otro carácter. Esto revela el amplio alcance del debido proceso; el individuo tiene el derecho al debido proceso entendido en los términos del artículo 8.1 y 8.2, tanto en materia penal como en todos estos otros órdenes" (Corte IDH, "Baena", 2001b, párr. $125)^{4}$.
}

\footnotetext{
${ }^{4}$ En igual sentido, Corte IDH, "Ivcher Bronstein vs. Perú", párr. 103. Corte IDH, "Vélez Loor vs. Panamá", Sentencia del 23 de noviembre de 2010, párr. 142. Corte IDH, OC N 18/03, párr. 124.
} 
Por ende, la Administración Pública no puede ejercer su potestad sancionatoria sin respetar las mencionadas "garantías procesales mínimas" reconocidas en Art. 8.1. y 8.2 de la CADH (Corte IDH, “Baena”, 2001b, párr. 126).

En efecto, si bien la Corte IDH no ha reconocido expresamente que el derecho al recurso en material laboral se derive del derecho a un recurso "efectivo y sencillo", el cual está dispuesto por el Artículo 25 de la CADH, también cabría traer a colación la interpretación que se hace de tal disposición convencional. Al fin y al cabo, tal como lo propone Calderón Gamboa, el citado artículo funciona como garantía para que existan recursos adecuados que permitan asegurar la vigencia material de los derechos fundamentales (2018, pp. 333-379). Porque, en efecto, los recursos no serían sino el medio por excelencia para asegurar el cumplimiento y, en su caso, las reparaciones que correspondan a los derechos que hubieran sido vulnerados.

Así, la Corte IDH ha establecido que, cuando se somete a los órganos judiciales el conocimiento de una decisión administrativa previa que se considera violatoria de los derechos de una presunta víctima, cabe analizar cuatro factores: a) la competencia del órgano judicial en cuestión; b) el tipo de materia sobre la cual se pronunció el órgano administrativo, teniendo en cuenta si ésta involucra conocimientos técnicos o especializados; c) el objeto de la controversia planteado ante el órgano judicial, lo cual incluye los alegatos de hecho y de derecho de las partes, y d) las garantías del debido proceso ante el órgano judicial (Corte IDH, 2011, Barbani Duarte y otros vs Uruguay, p. 203).

Lo más relevante a subrayar, es precisamente ese cuarto requisito, sobre el cual la Corte IDH ha establecido que para que se preserve el derecho a un recurso efectivo, en los términos del artículo 25 de la Convención, es indispensable que tal recurso se tramite conforme a las reglas del debido proceso, consagradas en el artículo 8 de la CADH (Corte IDH, Ximenes Lopes vs. Brasil, 2006a, párr. 127-128; Corte IDH, Claude Reyes y otros vs. Chile, 2006b, párr. 192-193; Corte IDH, Yatama vs. Nicaragua, 2005, párr. 147-149) . Y, tal como se ha expuesto en este trabajo, esas reglas del debido proceso suponen extender las garantías que caben en el proceso penal, a toda clase de procesos. Dicho de otra manera, la efectividad de los recursos judiciales en materia laboral — como en cualquier otra materiaconlleva que estos se adecúen a las garantías mínimas procesales que rigen en pleitos de naturaleza penal. 


\section{La recepción de la Suprema Corte de Justicia de la Provincia de Buenos Aires de la jurisprudencia interamericana sobre el derecho a la doble instancia en materia laboral}

\section{Toma I. Un control de convencionalidad negatorio: sobre la negación del derecho a una doble instancia en materia laboral}

Como se ha reseñado en este trabajo, el derecho al recurso se desglosa de las garantías procesales del derecho al debido proceso o también llamado "derecho a la tutela judicial efectiva" (Monterisi, 2011, pp. 767 y ss.). Tal argumento sostiene que este derecho ha sido reconocido por el Artículo 8.2. de la $\mathrm{CADH}$, el cual en su inciso $1^{\circ}$ dispone que "toda persona tiene derecho a ser oída, con las debidas garantías y dentro de un plazo razonable, por un juez o tribunal competente, independiente e imparcial, establecido con anterioridad por la ley, en la sustanciación de cualquier acusación penal formulada contra ella, o para la determinación de sus derechos y obligaciones de orden civil, laboral, fiscal o de cualquier otro carácter”. El inciso 2 posteriormente agrega que: "toda persona inculpada de delito", durante el proceso, tiene derecho a una batería de garantías mínimas, entre ellas el "derecho de recurrir del fallo ante juez o tribunal superior".

Ahora bien, existe una discusión bastante extensa en la jurisprudencia de la SCBA y de la CSJN sobre si ese derecho al recurso se ha de limitar exclusivamente a procesos de índole criminal o si cabe extenderlo a otras materias. Si bien tal discusión será abordada más detenidamente en apartados posteriores de esta investigación, basta decir por ahora, que ambos tribunales se han manifestado en contra de tal interpretación extensiva (SCBA, 2019a, Gigena, Oscar Aníbal contra Néstor F. Diez S.A. y otro/a. Daños y perjuicios, pp. 1-9; CSJN, Conductil S.A.C.I.F.I.A. c/ Music House Jujuy S.R.L. y otros s/Sumario 2007) ${ }^{5}$. Aún más, la SCBA explícitamente ha rechazado extender el derecho al recurso a supuestos no penales con el argumento de que la Corte IDH no se ha pronunciado explícitamente sobre el tema en la ratio decidendi de ningún caso contencioso (SCBA, "REM c/ Colegio de Kinesiólogos", 2011, pp. 8-11), ni en ejercicio de su jurisdicción consultiva (SCBA, Lozano, J. C. c/ Lavagnino Metalmecánica y otro s/ Despido, 2015, p. 36) ${ }^{6}$.

\footnotetext{
${ }^{5}$ En igual sentido, SCBA, Lozano, J. C. c/ Lavagnino Metalmecánica y otro s/ Despido, L. 116.822, 2015, p. 36; SCBA, 2011, "REM c/ Colegio de Kinesiólogos", p. 50; CSJN, Arce, Jorge Daniel s/ recurso de casación, 1997; CSJN, Martins, Raúl Luis s/ defraudación por retención indebida - causa N 105, 1996.

${ }^{6}$ En el caso "Lozano" cita una abundante jurisprudencia de la CSJN en la que este tribunal rechaza que la ausencia de una doble instancia laboral suponga una violación al derecho a la defensa en juicio. Sin embargo, no todos los precedentes a los que se hace referencia analizan el problema de la constitucionalidad del derecho a la defensa en juicio. En concreto, se cita CSJN (1959), pero allí se discute el acceso a la instancia extraordinaria en virtud de unas discrepancias entre los accionantes y lo resuelto por la Cámara Nacional del Trabajo en una sentencia que no resulta arbitraria. También se cita Fallos: 319:699 (1996), pero este es el caso "Martins, Raúl Luis s/ defraudación por retención indebida - causa $\mathrm{N}^{\circ} 105$-", una causa penal que no versa ni siquiera sobre el
} 
Con relación al sistema interamericano de derechos humanos, la SCBA, en un voto desarrollado por el juez Soria, ha reconocido que la Corte IDH ha extendido las garantías procesales del proceso penal a la materia civil, laboral, fiscal o de cualquier otro carácter (SCBA, "REM c/ Colegio de Kinesiólogos”, 2011, p. 50)․ . No obstante, el máximo tribunal bonaerense rechaza que la garantía de doble instancia se aplique extensivamente a cuestiones no penales (SCBA, "REM c/ Colegio de Kinesiólogos", 2011, p. 50). De hecho, la SCBA afirma expresamente que comparte el criterio de la Corte IDH, el cual asume que las garantías procesales en cuestiones laborales deben adecuarse a las garantías del proceso penal. Con todo, el citado tribunal bonaerense niega la posibilidad de exigir una doble instancia judicial, la cual es una de las pocas garantías del proceso penal que están expresamente reconocidas en el texto de la CADH.

Ahora bien, ¿de qué manera la SCBA aspira a salir de tal contradicción? ¿Con qué argumentos la SCBA pretende rechazar el derecho a una doble instancia judicial en causas de naturaleza no penal? ¿Cómo sostiene la compatibilidad de una única instancia con la pretensión de correspondencia o adecuación con lo dispuesto en el sistema interamericano de protección de derechos humanos? La respuesta que nos brinda el citado tribunal se basa en una lectura originalista de la CADH (SCBA, "REM c/ Colegio de Kinesiólogos", 2011, p. 50). Más en concreto, el voto del juez Soria afirma que en los trabajos preparatorios del citado tratado internacional se entendía que la garantía procesal establecida en el Artículo 8.2.h se refería exclusivamente a pelitos de naturaleza penal.

Sin embargo, no hace falta realizar una crítica al método interpretativo originalista aplicado por la SCBA para cuestionar la interpretación realizada por ese tribunal ${ }^{8}$. La solución adoptada por el tribunal es también cuestionable a partir de un cotejo de los trabajos preparatorios citado por el juez bonaerense, porque de las fuentes históricas no se sigue que la citada disposición convencional se haya referido exclusiva o taxativamente a cuestiones penales o criminales. De hecho, el artículo 8.2.h de la CADH ha sido escasamente debatido por los representantes estatales que elaboraron el mencionado tratado internacional. Aún más, tales representantes se limitaron a aprobar la citada disposición convencional, sin ninguna clase de discusión sobre su alcance, contenido o extensión (OEA, 1969, p. 202).

problema de la doble instancia, sino sobre la valoración de la prueba realizada en la sentencia impugnada. Lo mismo se advierte en la cita a "Grano, Marcelo Alejandro s/ abuso deshonesto agravado por el vínculo en concurso real con coacción”, Fallos: 324:2554 (2001).

${ }^{7}$ Aún más llamativo resulta que la SCBA haya citado a la "Opinión Consultiva $N^{\circ} 11 / 90$ ”, en la cual abiertamente se extiende el derecho al recurso a materias no penales.

${ }^{8}$ Para una reconstrucción sistemática del método y aporías de la interpretación originalista de los derechos fundamentales, ver Laise (2017). 
Un segundo argumento que emplea el máximo tribunal bonaerense es que la Corte IDH no se ha pronunciado en "forma clara y concreta en lo que tiene que ver con la doble instancia en los pleitos no criminales" (SCBA, "REM c/ Colegio de Kinesiólogos”, 2011, p. 49). Tal afirmación solo puede tenerse por correcta si nos referimos puntualmente a casos contenciosos que hayan tramitado ante la Corte IDH porque, como se ha expuesto en el segundo apartado de este trabajo, se ha advertido una Opinión Consultiva $\mathrm{N}^{\circ} 11 / 90$ en la que se ha extendido abiertamente el derecho a una doble instancia en casos penales o criminales. De hecho, la interpretación que la SCBA hace de tal Opinión Consultiva $N^{\circ}$ 11/90 parece confirmar lo dicho anteriormente.

Situados en este contexto de ideas cabría preguntarse, ¿bajo qué argumento la SCBA rechaza que la Opinión Consultiva $\mathrm{N}^{\circ} 11 / 90$ introduzca un derecho fundamental a la doble instancia judicial en materia extrapenal? Pues lo que arguye el máximo tribunal bonaerense es que tal Opinión Consultiva se refiere genéricamente al tema que nos ocupa. La SCBA se ocupa de remarcar, en efecto, que la Opinión Consultiva $\mathrm{N}^{\circ} 11 / 90$ trataba sobre "si se aplicaba el requisito de agotar los recursos internos a un indigente que, debido a circunstancias económicas, no era capaz de hacer uso de los recursos jurídicos" (SCBA, "REM c/ Colegio de Kinesiólogos”, 2011, p. 50). Por ende, esa Opinión Consultiva no habría planteado específica o puntualmente el derecho a la doble instancia en materia no penal como una garantía mínima, así lo ratifica la SCBA en el fallo Lozano, J. C. c/ Lavagnino Metalmecánica y otro s/ Despido, —en adelante: "Lozano" — (2015, p. 36).

De acuerdo con el entendimiento del máximo tribunal bonaerense, la Corte IDH no extendió el derecho a la doble instancia a cuestiones extrapenales, sino que habría sostenido tal extremo a modo de un obicter dictum. Aún más, la SCBA plantea que la Corte IDH "erróneamente" (la cita es directa, pero el destacado es nuestro) se refiere al derecho al recurso cuando aborda el tema de las garantías del debido proceso en el caso "Bronstein" (SCBA, "Lozano", 2015, p. 43) ${ }^{9}$. Con otras palabras, el excurso al derecho a una doble instancia en materia extrapenal habría sido indebidamente traído a colación en "Bronstein".

Finalmente, la SCBA hace una detallada narrativa de la jurisprudencia interamericana en materia de derecho a la doble instancia judicial en casos que no se subsumen a la materia penal. La conclusión a la que arriba el tribunal bonaerense es que la Corte IDH no ha aplicado un derecho a doble instancia a materias no penales. De hecho, incluso en casos como "Baena", en el cual se afirma el derecho a una doble instancia en materia administrativa, en rigor, tan

\footnotetext{
9 "Si bien el tribunal habla allí —erróneamente y obiter dictum — del art. 8.2.h., lo cierto es que a lo que está aludiendo es a la violación de las garantías judiciales en general que regula dicha norma, pero en ningún momento se dijo que faltó a la doble instancia (...)". [El énfasis figura en el original] (SCBA, 2015, p. 43).
} 
solo estaríamos ante un caso de procedimiento administrativo sancionatorio en el que, según la Corte IDH, cabría aplicar analógicamente las garantías propias del proceso penal (SCBA, “Lozano", 2015, p. 69).

Además, el llamado derecho al recurso no sería más que un argumento que complementa o refuerza el holding del caso; a saber, que un conjunto de irregularidades procesales implican una violación al principio del debido proceso legal. El punto central del caso "Baena", siempre de acuerdo con el máximo tribunal bonaerense, sería que la vía judicial no podía iniciarse directamente ante el órgano judicial de la máxima jerarquía; en particular, si antes de ello no hubo más que un proceso administrativo donde se habían violado todas las garantías procesales (SCBA, “Lozano”, 2015, pp. 62-63). En efecto, 'Baena' revela un cierto tratamiento de un derecho a la doble instancia en materia no penal, pero nuevamente no sería esto parte de la ratio decidendi de la sentencia de la Corte IDH (SCBA, "Lozano", 2015, p. $43)$.

En síntesis, la SCBA ha establecido que tanto la CADH como la jurisprudencia interamericana - consultiva y contenciosa - se limita a asegurar un derecho a la doble instancia en materia penal o criminal. De hecho, la doctrina establecida por la SCBA reduce el alcance del art. 8 inc. 2 "h" de la CADH a la garantía de que el litigante pueda ser oído con las debidas garantías por un tribunal competente, independiente e imparcial, establecido legalmente con anterioridad (SCBA, "Lozano", 2015; SCBA, Sampayo, Marcela A. contra Editora carpetas de derecho S.A. Despido. Rec. de queja, 2000).

Con todo, aunque tal doctrina judicial bonaerense no fue abiertamente modificada, y menos aún por medio de una referencia explícita a estándares interamericanos en materia de derechos humanos, podemos avizorar que se está avanzando hacia un paulatino reconocimiento de un derecho a la doble instancia judicial, tal como se verá en el caso Centauro S.A. c/ Ministerio de Trabajo de la Prov. de Bs. As. s/ Recurso de Queja", —en adelante: "Centauro" — que expondremos a continuación.

\section{Toma II. "Centauro": ¿un paso hacia el reconocimiento implícito de un derecho} a la doble instancia en materia laboral?

En el caso "Centauro", se discutió si las multas que impone el Subsecretario de Trabajo de la Provincia de Buenos Aires pueden ser apeladas o no en una segunda instancia judicial. Cabe tener presente que, según el artículo $61^{\circ}$ de la Ley $N^{\circ} 10.149$ de la Provincia de Buenos Aires 
"Las multas que imponga el Subsecretario de Trabajo podrán apelarse dentro del término de tres (3) días de notificado ante el Tribunal del Trabajo del lugar donde se cometió la infracción previo pago de la multa. El recurso deberá deducirse y fundarse ante la autoridad administrativa que impuso o notificó la sanción. Durante el procedimiento judicial, la Subsecretaría de Trabajo será representada por funcionarios autorizados" 10 .

En el reseñado caso, la SCBA se posicionó abiertamente a favor de la constitucionalidad del régimen de instancia única en materia laboral que impera en la Provincia de Buenos Aires, pero también ha flexibilizado algunos de los criterios de admisibilidad del recurso extraordinario provincial. De hecho, el máximo tribunal bonaerense afirma que no es la materia (derecho del trabajo) lo que habilita el acceso a la instancia extraordinaria. Con todo, la doctrina de "Centauro" permite avizorar que la SCBA, poco a poco, estaría inclinándose hacia un reconocimiento de un derecho al recurso en materia laboral más amplio que el que venía admitiendo tradicionalmente. Si bien es cierto que no se hace referencia en algún momento a estándares internacionales o regionales en lo que hace a los derechos humanos, es posible advertir que se interpreta la admisibilidad de un recurso extraordinario por inaplicabilidad de la ley con un criterio menos restrictivo cuando se está frente a casos laborales en que se controvierten actos de la autoridad administrativa provincial.

No obstante, es preciso destacar que la SCBA ratifica la necesidad de cumplir con algunos de los requisitos típicos del acceso a su jurisdicción extraordinaria como, por ejemplo, la acreditación de que la decisión judicial impugnada presente el carácter de definitiva o equiparable a esta (SCBA, "Centauro", 2019b, pp. 4 y 5). En el caso, en efecto, tal extremo habría sido tenido por acreditado, en tanto y en cuanto el órgano jurisdiccional judicial había denegado la apelación y, en el mismo acto, confirmó lo resuelto por la autoridad administrativa. Así, la decisión del Tribunal del Trabajo terminó por ordenar que, una vez consentida la multa, se proceda a su ejecución inmediata (SCBA, "Centauro", 2019b, p. 5).

De hecho, la SCBA mantuvo la doctrina en virtud de la cual la parte apelante ha de cumplir con el requisito del depósito judicial previo que dispone el Artículo 280 del Código Procesal Civil y Comercial de la Provincia de Buenos Aires. Con otras palabras, se amplió el criterio de admisibilidad, pero no se modificaron las exigencias formales que han de caracterizar a un recurso extraordinario que tramita ante la SCBA.

\footnotetext{
${ }^{10}$ Cabe aclarar que la Ley $\mathrm{N}^{\circ} 10.149 / 84$ de la Provincia de Buenos Aires regula la jurisdicción, atribuciones y procedimiento de la Subsecretaría de Trabajo de esa provincia.
} 


\section{Balance crítico: un deficiente control de convencionalidad ante un sujeto de especial protección constitucional}

\section{El argumento de la inconsistencia lógica: una conclusión que no se deriva de las premisas asumidas por la SCBA}

La doctrina negatoria del derecho a la doble instancia en materia laboral no resulta consistente en términos de lógica jurídica. Porque la práctica del control de convencionalidad exige, a nuestro modo de ver, una solución exactamente contraria a la que arribó la SCBA. De esta manera, si el máximo tribunal bonaerense asume, junto con la Corte IDH, que en cuestiones civiles y laborales resulta preciso observar las mismas garantías procesales mínimas del debido proceso que se han de respetar en materia penal; pues entonces cabría extender la garantía de la doble instancia a procesos civiles, laborales o fiscales.

En efecto, si la SCBA pretende ser coherente con la Corte IDH, no puede basarse en la doctrina de ese tribunal interamericano para afirmar que, en todos los procesos judiciales, de la naturaleza que fuera, rigen las mismas garantías mínimas que en el proceso penal y, a la par, rechazar uno de los contenidos — derecho al recurso en materia no penal- que el tribunal interamericano atribuye expresamente a tales garantías mínimas. De lo contrario, la SCBA estaría afirmando que a los procesos laborales se ha de aplicar los mismos estándares del proceso penal, pero uno de ellos -el derecho a la doble instancia - no tiene lugar en la justicia laboral bonaerense. En otras palabras, la jurisprudencia de la SCBA no resulta consistente al afirmar que aplica unos estándares convencionales en materia de garantías procesales y, al mismo tiempo, se niega a extenderlos a supuestos que expresamente recoge la Corte IDH.

El argumento axiológico: una interpretación del derecho a la defensa en juicio desarticulada del principio protectorio en materia laboral

Existe un segundo punto a considerar que tiene que ver menos con la consistencia lógica y más con la axiología constitucional. Con esto se pretende sostener que ha de tenerse presente que hay un particular sujeto que está involucrado en casos en los que se discute el derecho a una doble instancia judicial. Más precisamente nos referimos al trabajador, el cual es considerado por la CSJN como un "sujeto de preferente tutela constitucional" (CSJN, Ascua, Luis Ricardo c/ SOMISA s/ cobro de pesos, 2010, Consid. 5; CSJN, 2009, Pérez, Aníbal Raúl c/ Disco S.A Consid. 4; CSJN, Vizzoti, Carlos c/ AMSA S.A. s/ Despido, 2004a, Consid. 1).

Lo que se quiere poner de relieve es un punto que nos parece importante abordar, ¿cabe admitir la constitucionalidad de la única instancia cuando estamos frente a un sujeto de 
preferente tutela constitucional como es el trabajador? La respuesta de la SCBA no brinda argumentos que enlacen la constitucionalidad de la única instancia laboral y la preferente tutela constitucional que le corresponde al trabajador. Aún más, el máximo tribunal bonaerense rechaza la posibilidad de doble instancia, sin atender a las cualidades particulares de las partes involucradas.

Tal categorización del trabajador como "sujeto de preferente tutela constitucional" se desprende del principio protectorio del derecho del trabajo que se encuentra recogido por el Artículo 14 bis de la Constitución de la Nación Argentina y del plexo de tratados internacionales de derechos humanos que, de acuerdo con el Art. 75, inciso 22 de la Constitución Nacional, gozan de rango constitucional (CSJN, Vizzoti, Carlos c/ AMSA S.A. s/ Despido, 2004a, Consid. 10; CSJN, Aquino, Isacio c/ Cargo Servicios Industriales S.A. s/ accidentes ley 9688, 2004b, Consid. 10). De esta manera, si la "preferente tutela constitucional" es un desglose del principio protectorio, pues entonces tal preferencia conlleva el propósito de nivelar desigualdades (Pasco, 1994, pp. 149 y 152). En otras palabras, el fundamento de que los trabajadores dispongan de una preferente tutela constitucional no es sino la posición desaventajada en la que se encuentran frente al empleador.

En tal sentido, la Sala VII de la Cámara Nacional de Apelaciones de Trabajo (CNAT), si bien no ha abordado directamente la cuestión del derecho a una doble instancia en materia laboral, sí ha sostenido que tanto el principio protectorio como el carácter de sujeto de preferente tutela constitucional del trabajador se proyectan sobre la interpretación de normas procesales (CNAT, Herrera, Ángel Gustavo c/ Prevención Art. S.A. s/ Accidente - Ley Especial, 2016). El mencionado tribunal sostuvo entonces que el empleador había contratado una aseguradora de riesgo del trabajo con domicilio en la ciudad de Sunchales, provincia de Santa Fe y, por lo tanto, resultaría claro que el pleito debía tener lugar en esa ciudad santafesina, de acuerdo con el artículo $24^{\circ}$ de la Ley Nacional $N^{\circ} 18.345 / 69$ — Ley de Organización y Procedimiento de la Justicia Nacional del Trabajo- . No obstante, el tribunal interviniente resolvió que una aplicación estricta de tal norma procesal hubiera implicado una vulneración del derecho al acceso a la justicia. De esta manera, se estableció que no cabía hacer recaer sobre el trabajador, la carga de llevar adelante un pleito sobre un accidente en el trabajo, en una jurisdicción distinta a la que había celebrado y ejecutado su contrato laboral.

A nuestro modo de ver, el caso "Herrera" revela una acertada estrategia argumentativa; esto es, subraya que es preciso interpretar el alcance de las normas procesales laborales a la luz de la consideración del trabajador como "sujeto de preferente tutela constitucional", en 
virtud de la desigual posición en la cual este se encuentra frente al empleador ${ }^{11}$. Con todo, lo que más interesa remarcar, es que el "tratamiento preferente" del trabajador ha de complementarse con un principio de suma importancia en el plano de la interpretación de los derechos fundamentales: el principio pro homine. Esto supone, que en caso de que existan dudas acerca de la interpretación que debe asignarse a una disposición o norma jurídica, cabe inclinarse por la interpretación más favorable a los derechos de la persona afectada (Pinto, 1997, p. 163).

Situados en este contexto, resulta especialmente llamativo que la SCBA adopte un criterio tan limitativo del derecho a la defensa en juicio (Vittar, Eduardo Calim contra Todo Quebracho S.A. Cobro de australes, 1994), incluso en casos donde se encuentran involucrados "sujetos de preferente tutela constitucional" como son los trabajadores (SCBA, Gigena, Oscar Aníbal contra Néstor F. Diez S.A. y otro/a. Daños y perjuicios, 2019a, p. 6). De hecho, la SCBA rechaza el derecho a una doble instancia judicial, pero sin distinguir de modo alguno si quien reclama tal derecho se encuentra o no en una situación que reclama una especial protección por parte de los órganos del Estado. En efecto, la particular situación de vulnerabilidad en que se ubica el trabajador reclama, como mínimo, que la SCBA brinde una consideración sólida sobre cómo es que un régimen de única instancia no refuerza el mencionado estado de indefensión.

\section{El argumento hermenéutico: una deficiente referencia implícita al margen nacional de apreciación}

El tercer argumento por examinar consiste en determinar si el establecimiento de una instancia única podría sostenerse sobre la base de lo que la doctrina y jurisprudencia internacionalisra designa como "margen nacional de apreciación". Esta doctrina, que no es expresamente recogida por la SCBA, pareciera ser aplicada, pero sin ser mencionada en momento alguno. Porque el rechazo a considerar a la doble instancia como parte de las "garantías procesales mínimas" que reconoce la $\mathrm{CADH}$, tácitamente sugiere que el Estado argentino tiene la posibilidad de escoger libre y discrecionalmente si consagra una doble instancia en materias no penales, lo cual no estaría violando el contenido básico del derecho a la defensa en juicio y el derecho a recursos efectivos frente a violaciones de derechos fundamentales. Por ende, la doble instancia laboral sería tan solo un aspecto contingente del derecho de la defensa en juicio que cada estado podría o no reconocer.

\footnotetext{
${ }^{11}$ Para una caracterización sobre la naturaleza e implicancias del principio protectorio en el derecho procesal del trabajo, Pasco Cosmópolis (1994).
} 
Sin embargo, esto presenta una dificultad teórica que desemboca en otra de naturaleza práctica u operativa. Más específicamente, la Corte IDH no ha incorporado el margen nacional de apreciación strictu sensu en sus prácticas interpretativas, tal como lo ha señalado Nash (2018). Cabe aclarar que, cuando se hace referencia al margen de apreciación en sentido estricto, se plantea un espacio de inhibición de la protección internacional en deferencia de la apreciación nacional sobre el contenido de elementos normativos indeterminados propios de la protección internacional de derechos humanos (Nash, 2018, p. 85). Se derivaría de tal margen, en efecto, una deferencia hacia las regulaciones internas sobre un particular derecho fundamental ante supuestos en los que no existe un consenso o acuerdo generalizado a nivel interestatal (Barbosa, 2012, pp. 51-82).

Así, el margen nacional de apreciación resulta ser un criterio hermenéutico que guía a la interpretación y aplicación de los derechos humanos, el cual es atribuido por parte de un tribunal internacional y que se dirige hacia los estados nacionales. Aquí es donde este argumento teórico colapsa en un inconveniente práctico para justificar un régimen procesal de instancia única. En concreto, la Corte IDH es renuente a brindarle alguna clase de deferencia a las regulaciones de derecho interno bajo el prisma de que son cuestiones debatidas o sobre las que no se advierte un nítido acuerdo a nivel internacional. De hecho, el rechazo a esa doctrina por parte de la jurisprudencia interamericana responde a que la Corte IDH entiende que no se estaría hablando del espacio para la implementación de los derechos humanos en sede nacional, sino de una invocación del derecho interno para excusar el cumplimiento de obligaciones internacionales (García, 2011, p. 128).

En efecto, como se ha dicho en este trabajo, si bien la jurisprudencia interamericana no ha tematizado directa o centralmente el asunto del derecho a una doble instancia en materia extrapenal, lo cierto es que en ningún momento sugirió que tal derecho se limitase meramente a casos criminales o penales. Tampoco la Corte IDH ha manifestado — aún más: ni siquiera ha insinuado - que la exigencia de una doble instancia sea una cuestión netamente sujeta a lo que disponga cada Estado. Antes bien, la Corte IDH ha sostenido reiteradamente que el derecho al recurso, incluso en materia extrapenal, resulta ser una parte del contenido del derecho a la defensa en juicio que reconoce la $\mathrm{CADH}$.

Porque si la única vía de impugnación para una sentencia de primera y única instancia laboral es por medio de un recurso extraordinario, ¿podría afirmarse que existe un recurso "efectivo y sencillo" para tutelar a los derechos de los trabajadores? La respuesta negativa se impone en virtud de la rigidez de los criterios de admisibilidad de un recurso extraordinario y, sobre todo, el escaso margen de debate sobre valoración de prueba y derecho aplicable que 
se sigue de tal instancia extraordinaria, parecen sugerir que la falta de una doble instancia conlleva una violación del Artículo 25 de la CADH.

Con todo, podría afirmarse que una doble instancia sería, en rigor, desfavorable para los empleados. Esta objeción es uno de los argumentos más convincentes para el rechazo de una doble instancia en materia laboral. Tal argumento sostiene que adicionar una instancia judicial redundaría en procesos todavía más extensos en el tiempo, lo cual sería claramente perjudicial para las partes (Ibarlucía, 2010, pp. 870 y ss.) ${ }^{12}$; pero muy especialmente para los trabajadores. La próxima sección de este trabajo pretende responder a tal objeción.

\section{¿Es la doble instancia perjudicial para la defensa de los trabajadores? Respuesta a la objeción consecuencialista}

El argumento consecuencialista tiene un atractivo notable, porque implicaría que se terminaría perjudicando a un grupo de personas bajo el pretexto de ampliar su derecho a la defensa en juicio. Esto sería especialmente grave porque una de las partes —el trabajadorya se encuentra en un estado de desigualdad con la otra parte de un litigio de índole laboral. Sería un paradigmático ejemplo de un remedio que es peor que la enfermedad. No se trata de una posibilidad hipotética. De hecho, la tendencia latinoamericana parece decantarse claramente hacia una lentitud generalizada de los procesos judiciales de índole laboral (Barbagelata, 2002, pp. 27 y 29). Argentina se ubica entre los países con los procesos menos expeditivos y la Provincia de Buenos Aires no es la excepción. En tal jurisdicción, se estima que un juicio sencillo como, por ejemplo, un despido con una mera pericia contable estaría tardando unos dos años para el dictado de una sentencia definitiva (Arese, 2015, pp. 237, 247 y 248).

Sin embargo, a nuestro modo de ver, ese argumento incurre en una forma especialmente perniciosa de falacia; la petición de principios. Ahora bien, ¿qué es una petición de principios? Sintéticamente cabría decir que existen dos clases de maneras de incurrir en tal falacia: 1) cuando se utiliza como premisa lo mismo que afirma la conclusión o algo cuya verdad depende de ella; o bien 2) porque se utiliza como premisa algo cuya veracidad no está probada (García, 2000, p. 73; Damer, 2008, pp. 69 y 70; Aristóteles, 1967, Cap. 13, 162b, 3155). Este último caso, en efecto, es la principal dificultad del argumento consecuencialista que se esgrime en rechazo de la doble instancia en sede laboral. Más en concreto, se tiene por probado algo que resta demostrar.

\footnotetext{
${ }^{12}$ En un sentido similar, Kielmanovich (2006).
} 
No se hace aquí referencia a la congestión judicial, el cual es un hecho de notorio conocimiento público y, por ende, que no hace falta demostrar, al menos en el ámbito hispanoamericano (Estigarribia de Midón \& Midón, 2014, pp. 309-310). Lo que resta por evidenciar son las causas de esa manifiesta congestión judicial. Se trata, en efecto, de un punto de central relevancia. En un polo extremo, tal fenómeno podría ser una consecuencia de un uso irresponsable del servicio de justicia y, en el otro, tal congestión sería el resultado de una impericia o negligencia de los jueces laborales en la gestión de sus despachos judiciales. Y, naturalmente, caben múltiples combinaciones posibles que pongan el acento —en mayor o menor medida - en alguno de tales extremos. También cabe imaginar un supuesto de responsabilidades igualmente concurrentes.

En cualquier caso, el argumento consecuencialista debe probar con evidencia empírica que la función judicial no está congestionada principal o mayormente en virtud de su impericia o incompetencia profesional ${ }^{13}$. De lo contrario, se terminaría rechazando que los justiciables tengan un derecho a una segunda instancia por algo que, en último lugar, no se sabe si es o no producto de un desgobierno en la administración del servicio de justicia. Porque, en efecto, la falta de estudios de corte empírico y sociológico sobre el congestionamiento de la justicia laboral no permite rechazar, como tampoco defender, que la congestión obedece a tal o cual razón. Dicho de otra manera, no disponemos de información para exonerar o atribuir responsabilidad a los jueces o a los abogados litigantes por la congestión judicial.

Ahora bien, si no sabemos a qué causa responde la congestión judicial, ¿cabría rechazar la segunda instancia judicial? A nuestro modo de ver, el principio protectorio y, sobre todo, el principio de in dubio pro operario exigen una respuesta negativa. Alguien podría objetar, ¿pero acaso la defensa de una doble instancia no debería argumentar que resulta efectivamente más tuitiva del trabajador? Para no incurrir en la misma falacia que se achaca resulta preciso brindar una respuesta a tal interrogante.

En primer lugar, la ineficiencia del poder judicial para tramitar los procesos laborales que tramitan ante a él no resultaría ser una causa suficiente para excusar al Estado argentino frente a la violación del derecho a la defensa en juicio. Si bien es cierto que la Corte IDH no se ha pronunciado directa y focalmente sobre el deber de asegurar una doble instancia en materia laboral, las sentencias reseñadas no parecen sugerir que las garantías procesales reconocidas en la CADH se circunscribirán pura y exclusivamente a la materia penal, tal como se ha expuesto en secciones anteriores de este trabajo.

\footnotetext{
${ }^{13}$ En este punto me inspiro en Damer, quien plantea que la petición de principios supone una premisa definicional que se apoya, implícita o explícitamente, en un dato empírico que se tiene por probado pero que, en rigor, se encuentra bajo discusión (2008, p.70).
} 
En segundo lugar, si no sabemos a quién cabe responsabilizar primordial o principalmente por la congestión judicial, ¿resulta proporcionado restringir el acceso a la vía de impugnación a los trabajadores? Una respuesta a nivel judicial, mientras se implementan los juzgados de segunda instancia en materia laboral, debería procurar conciliar el derecho a la defensa en juicio, tanto de la patronal como de los empleados, y el cumplimiento del principio protectorio. ¿Eso podría implicar un tratamiento diferenciado de las vías recursivas a disposición de las partes? Creemos que sí.

Sin embargo, no se trataría de un tratamiento desigual que fuera calificable como arbitrario o irrazonable. Se quebraría la columna vertebral del principio de bilateralidad si se impidiera que la parte empleadora tenga universalmente vedado el acceso a un recurso y no el empleado. De hecho, estimamos que sí se podría reservar la vía recursiva a algunos supuestos basados en determinados factores tales como pleitos que no sean de baja cuantía o vulneración de derechos del trabajador especialmente graves $-p$. e., despidos arbitrarios de representantes sindicales; despidos injustificados de mujeres embarazadas; acosos laborales que llevan conexo un proceso penal; accidentes de trabajo que desembocan en una incapacidad mayor del 75\%, por mencionar solo algunos supuestos-.

\section{Una propuesta interpretativa: la armonización del derecho interno con la práctica del control de convencionalidad que realiza la Corte Interamericana de Derechos Humanos}

En este trabajo no se pretende formular una propuesta de lege ferenda que apunte a derogar o suplantar a las normas y disposiciones jurídicas del derecho interno por estándares internacionales de derechos humanos en materia de un derecho al recurso que aseguren una doble instancia judicial en materia no penal. En efecto, este artículo emprenderá un camino sustancialmente distinto. Lo que se propondrá, por el contrario, será adoptar una interpretación del derecho interno que complemente y resulte compatible con dos extremos; por un lado, las prácticas interpretativas que la Corte IDH lleva a cabo (Bazán, 2015, pp. 25 y 36) y una interpretación sistemática de la jurisprudencia de la CSJN.

Más en concreto, lo que se propone aquí no necesaria o únicamente supone una mera declaración de inconstitucionalidad del régimen de única instancia en materia laboral en la Provincia de Buenos Aires - Artículo 2, inciso a, Ley provincial $\mathrm{N}^{\circ} 1165$-, sino también la posibilidad de que la SCBA flexibilice las exigencias para el trámite de recursos impugnativos en materia laboral. Dicho con otras palabras, la expansión de la jurisdicción extraordinaria bonaerense también podría satisfacer el derecho a una doble instancia en materia laboral. 
Si bien es cierto que esto podría incrementar la carga de trabajo de la SCBA, también se podría pensar que el escaso margen de impugnación que supone el procedimiento laboral conlleva a la interposición de múltiples recursos extraordinarios tanto a nivel provincial como luego a nivel federal que aumentan el caudal de expedientes que tramitan ante la CSJN y la SCBA (Egües, 2007, pp. 925 y ss.). Y, por ende, la falta de reconocimiento de una vía de apelación sería precisamente una de las causas del congestionamiento judicial. En cualquier caso, vale tener presente que la consagración de una doble instancia en supuestos laborales no tiene que extenderse necesariamente a todo el universo de casos laborales.

La SCBA podría, por ejemplo, delinear algunos límites para los casos en que intervendrá como una suerte de tribunal de alzada; o bien podría remitir alguno de esos casos para que otros tribunales del trabajo - distintos al que resolvieron el caso en primera instancia - resuelvan determinados expedientes por vía de apelación ordinaria. En efecto, si vemos a la doble instancia como un principio, y no como una regla, cabría reconocer que admite diversos grados de cumplimiento (Alexy, 1993, p. 86). Más en concreto, se podría, al menos, reconocer el derecho a la doble instancia laboral en algunos supuestos que incrementan o potencian un particular estado de indefensión del trabajador como, por caso, despidos arbitrarios de personas en alta situación de vulnerabilidad socioeconómica $-p$. e., madres embarazadas, padres o tutores de personas discapacitadas - o graves demandas por acoso laboral.

Cabría aclarar que la eventual declaración de inconstitucionalidad del régimen de instancia única no implica negar la posibilidad de trazar límites a ese derecho. Se podría elaborar una sentencia de constitucionalidad condicionada, como diría la Corte Constitucional de Colombia (Sentencia C-355, 2006); es decir, se podría declarar inconstitucional al régimen de única instancia en material laboral, pero cuando se incurriera en determinados supuestos. Con todo, cabe remarcar que lo anterior no supone la práctica de un control de constitucionalidad en abstracto.

Porque los supuestos en que se construiría el sentido del derecho a la doble instancia en materia laboral se podrían ir desarrollando a partir de casos concretos que lleguen a la jurisdicción de la SCBA, los cuales terminarían formando una red de precedentes, que poco a poco, desembocaría en un conjunto de reglas que concretarían la vigencia material del contenido mínimo del derecho al recurso en contextos laborales (Toller, 2014). Tal conjunto de reglas brindaría criterios que irían constriñendo y guiando a los jueces inferiores al momento de resolver sentencias (Clérico, 2015, pp. 73 y 89). Porque con el paso del tiempo, se elaboraría una "red de puntos de vista concretos y reglas para la aplicación del respectivo 
derecho fundamental", tal como Clérico lo indica (2015, p. 89). De esta manera, paulatinamente se podría cumplir con la finalidad básica del derecho al recurso; a saber, dotar al justiciable de canales para impugnar sentencias judiciales y así evitar que se refuerce el estado de indefensión propio del trabajador.

También cabría tener presente que a partir del caso "Lagos del Campo vs. Perú" se advierte una creciente relevancia que se le atribuye a la justiciabilidad de los derechos sociales, económicos y culturales en la Corte IDH. En tal sentencia, se examinaron los límites de la estabilidad laboral y el tribunal aprovechó la ocasión para subrayar la indivisibilidad entre los derechos civiles y políticos y los derechos sociales, económicos y culturales. Más aún, el caso "Lagos del Campo vs. Perú" reiteró que ambos tienen la misma jerarquía y que resultan igualmente exigibles ante las autoridades competentes (Corte IDH, 2017a, párr. 141).

Así, se puede apreciar que existe una tendencia en la jurisprudencia interamericana que pretende erradicar toda diferenciación entre la exigibilidad judicial de los derechos basados en su naturaleza "positiva" o "negativa”. Más aún, si la Corte IDH sostiene que todos los derechos poseen la misma jerarquía, ¿cabría esperar que la Corte IDH siga mostrándose condescendiente ante la ausencia de una doble instancia en materia laboral, bajo el argumento de que no estamos ante un caso de índole criminal o penal? ¿Existen indicios que nos permitan inferir que la Corte IDH se retractará de su Opinión Consultiva $\mathrm{N}^{\circ} 11 / 90$ en la cual aclara expresamente que el derecho al recurso se extiende no solo a procesos penales, sino también a procesos laborales, civiles, administrativos y fiscales? El constante incremento del compromiso que el citado tribunal interamericano mantiene con el principio de unidad entre los derechos humanos y con el principio de progresividad en materia de derechos humanos parece indicarnos una respuesta negativa a tales interrogantes.

Por consiguiente, el rechazo a instituir pretoriana o legalmente un sistema de doble instancia podría acarrear responsabilidad internacional del Estado argentino. Más aún, si se argumentase que los criterios adoptados por los jueces nacionales no han procurado articular las interpretaciones del derecho vigente a los estándares aplicados por la Corte IDH. Porque debe tenerse presente, que el antedicho tribunal ha sostenido que "(...) es competente para ordenar a un Estado que deje sin efecto una ley interna cuando sus términos sean violatorios de los derechos previstos en la Convención y cuando esto haya sido demostrado" (Corte IDH, Trabajadores Cesados de Petroperú vs. Perú, 2017b, p. 68).

De hecho, la CSJN ha reiterado la deferencia que le debe a la Corte IDH, incluso en el polémico caso "Fontevecchia" (CSJN, 2017, Consid. 8). Allí se mantuvo en pie la doctrina de la CSJN que le asigna a la Corte IDH el carácter de intérprete final de la CADH. Su punto 
más debatido fue una medida de reparación consistente en la revocación de una sentencia de la CSJN. Lo que se pretende subrayar, pues, es que la jurisprudencia del máximo tribunal argentino sigue sosteniendo que la CADH rige en las "condiciones de su vigencia"; es decir, “tal como la Convención citada efectivamente rige en el ámbito internacional y considerando particularmente su efectiva aplicación jurisprudencial por los tribunales internacionales competentes para su interpretación y aplicación" (CSJN, Giroldi Horacio David y otro s/Recurso de Casación, 1995, Consid. 11). De ahí que la jurisprudencia interamericana "deba servir de guía para la interpretación de los preceptos convencionales en la medida en que el Estado Argentino reconoció la competencia de la Corte IDH para conocer en todos los casos relativos a la interpretación y aplicación de la CADH (...)” (CSJN, Giroldi Horacio David y otro s/Recurso de Casación, 1995, Consid. 11).

\section{Balance conclusivo: algunas consideraciones para el período en que agoniza el régimen procesal de instancia única en materia laboral de la Provincia de Buenos Aires}

Carece de suficiente justificación que la SCBA mantenga su criterio de restringir el derecho al recurso a una doble instancia en materia penal, incluso luego de la reforma del régimen procesal en materia laboral que rige en tal provincia. Si bien es cierto que todavía el Estado argentino no ha sido condenado por violar la $\mathrm{CADH}$ por no asegurar una doble instancia en cuestiones no criminales, también se ha de subrayar que los últimos precedentes de la Corte IDH, en materia de derechos sociales, permiten anticipar la línea que adoptaría para el caso en que no se asegurase a un "sujeto de preferente tutela constitucional" el derecho a una revisión integral de una sentencia en el marco de una segunda instancia en material laboral.

El rechazo de la jurisprudencia bonaerense al derecho a un recurso que garantice una doble instancia se ha basado en interpretaciones literales y originalistas de la CADH. Y, de un modo elíptico, se asume un cierto margen nacional de apreciación. Cada uno de los argumentos esgrimidos por la jurisprudencia y la doctrina para defender la constitucionalidad de un régimen de instancia única en materia laboral, han sido discutidos críticamente en el presente trabajo.

En concreto, los argumentos basados en metodologías interpretativas de tipo literal $\mathrm{u}$ originalistas se encuentran en tensión con las interpretaciones que actualmente brinda la Corte IDH al derecho al recurso. Y las consideraciones sobre que la jurisprudencia interamericana no se ha manifestado expresamente sobre el sentido de la doble instancia en materia extrapenal, parecen insuficientes, tanto por la creciente flexibilización de los recaudos 
formales para acceder a la jurisdicción de la Corte IDH, como por la notable expansión de la justiciabilidad de los derechos sociales, económicos, culturales y ambientales que viene realizando ese tribunal.

Por ende, frente a un robusto compromiso de la Corte IDH por asegurar estándares de cumplimiento más ambiciosos en lo que respecta a derechos sociales, parece ingenuo pensar que ese tribunal se mantendrá pasivo frente a violaciones de las garantías procesales de los trabajadores. Mucho más en el período de transición entre la instauración de un régimen de doble instancia laboral y su efectiva implementación por medio de la plena conformación de todas las salas de la Cámara de Apelación del Trabajo de la Provincia de Buenos Aires.

El argumento del margen nacional de apreciación luce teórica o dogmáticamente plausible para justificar el régimen de instancia única, pero esa línea argumental viene siendo rechazada tajantemente por la jurisprudencia interamericana. De hecho, la Corte IDH no se ha autorrestringido frente a cuestiones debatidas a nivel interestatal que se llevan a su consideración bajo el concepto de "violaciones a los derechos humanos". Antes bien, la Corte IDH parece ver a la doctrina del margen nacional de apreciación como una inaceptable excusa para incumplir el derecho internacional de los derechos humanos por medio de la invocación del derecho interno.

El argumento que se muestra más sólido para rechazar que la doble instancia integre el derecho a la defensa en juicio o tutela judicial efectiva, es lo que se ha dado en llamar "argumento consecuencialista". Tal argumento defiende que se derivarían consecuencias perjudiciales para el trabajador, en el caso que se consagre la obligatoriedad de un régimen de segunda instancia. Porque se terminarían por alargar — todavía más - los de por sí extensos juicios laborales. No obstante, hemos sostenido que ese argumento, al menos con la información disponible a la fecha, supone una "petición de principios".

Más en concreto, el argumento consecuencialista supone que el Poder Judicial no tiene la responsabilidad principal en el congestionamiento de los juzgados. Puesto que no se conoce el nivel de congestión de los juzgados laborales de la Provincia de Buenos Aires, y menos aún, las causas de tal fenómeno, se termina haciendo recaer sobre los justiciables una consecuencia que ni siquiera se sabe si responde a conductas procesales irresponsables del grueso de los abogados que llevan adelante casos laborales o si tal congestión obedece a la impericia en lo que respecta a la gestión del trabajo judicial. Toda una gama de combinaciones posibles, con mayor o menor cuota de responsabilidad sobre jueces o abogados litigantes, podría ser la explicación de los retrasos en la administración de la justicia laboral. 
Ahora bien, frente a las dificultades para atribuir responsabilidades por la congestión judicial, este trabajo finalmente propuso una declaración de inconstitucionalidad del régimen de instancia única en materia laboral. Sin embargo, esa declaración bien podría estar condicionada a unos determinados tipos de casos. Se trataría de algo semejante a lo que la jurisprudencia constitucional colombiana llama como "sentencia de constitucionalidad condicionada"; esto es, se podría circunscribir la inconstitucionalidad o constitucionalidad de la norma bajo examen a unos determinados supuestos de hecho.

En síntesis, la SCBA podría declarar que existe un derecho a recurrir, pero no aplicable a cualquier sentencia que verse sobre el derecho al trabajo, sino solamente para aquellas resoluciones judiciales en que se vean involucrados trabajadores o empleadores en grave situación de vulnerabilidad socioeconómica o ante supuestos que sería de difícil o imposible reparación ulterior.

Podría pensarse que cabe tener una veta de esperanza en virtud de una cierta flexibilización de los requisitos para acceder a la jurisdicción extraordinaria de la SCBA cuando se discuten actos de la autoridad administrativo provincial que involucran a trabajadores, tal como se vio en el reciente caso "Centauro". Con todo, queda mucho camino por recorrer para asegurar que los trabajadores dispongan de una posibilidad amplia para impugnar decisiones judiciales hasta que se efectivice completamente la Cámara de Apelación del Trabajo en la Provincia de Buenos Aires.

\section{Referencias bibliográficas}

\section{Libros y artículos de doctrina}

Alexy, R. (1993). Teoría de los derechos fundamentales (Trad. E. Garzón Valdés). Madrid, España: Centro de Estudios Políticos y Constitucionales.

Arese, C. (2015). El acceso a la tutela judicial efectiva laboral. Revista Latinoamericana de Derecho Social, 21(2), 237-256. Recuperado el 21 de marzo de 2020 de: https://revistas.juridicas.unam.mx/index.php/derecho-social/article/view/9771

Aristóteles (1967). Tópicos, en Obras Completas (Trad. F. P. Samaranch). Madrid, España: Aguilar.

Barbagelata, H. H. (2002). Tendencias de los procesos laborales en Iberoamérica. Revista de la Facultad de Derecho, 21(21), 27-44. Recuperado el 21 de marzo de 2020 de: https://revista.fder.edu.uy/index.php/rfd/article/view/229/250

Barbosa Delgado, F. R. (2012). El margen nacional de apreciación en el derecho internacional de los derechos humanos: entre el Estado de derecho y la sociedad democrática. En P. A. Acosta Alvarado \& M. Núñez Poblete (Eds.), El margen de apreciación en el sistema interamericano de derechos humanos: proyecciones regionales y nacionales (pp. 51-82). México D.F., México: Instituto de Investigaciones Jurídicas, U.N.A.M.

Bazán, V. (2015). El control de convencionalidad como instrumento para proteger derechos esenciales y prevenir responsabilidad internacional del estado. Anuario Iberoamericano de Justicia 
Constitucional, 19, 25-70. Recuperado el 20 de febrero de 2020 de https://recyt.fecyt.es/index.php/AIJC/article/view/42043

Calderón Gamboa, J. (2018). La puerta de la justiciabilidad de los derechos económicos, sociales, culturales y ambientales en el sistema Interamericano: relevancia de la sentencia Lagos del Campo. En E. Ferrer Mac-Gregor, M. Morales Antoniazzi \& R. Flores Pantoja (Eds.), Inclusión, Ius Commune y Justiciabilidad de los DESCA en la jurisprudencia interamericana: el caso Lagos del Campo y los nuevos desafios (pp. 333-379). México D.F., México: Universidad Nacional Autónoma de México. Instituto de Investigaciones Jurídicas. $\begin{array}{lllllll}\text { Recuperado } & \text { el } & 22 & \text { de } & \text { febrero } & \text { del } & 2020\end{array}$ https://archivos.juridicas.unam.mx/www/bjv/libros/10/4817/9.pdf

Clérico, L. (2015). Examen de proporcionalidad y objeción de indeterminación. Anuario de Filosofía del Derecho, 31, 73-99. Recuperado el 20 de febrero del 2020 de https://dialnet.unirioja.es/descarga/articulo/5231548.pdf

Damer, T. E. (2008). Attacking Faulty Reasoning: A Practical Guide to Fallacy-Free Arguments. Belmont, Estados Unidos de América: Wadsworth.

De Midón, E., Gladis, H. \& Midón, M. S. (2014). Manual de derecho procesal civil. Buenos Aires, Argentina: La Ley.

Egües, A. J. (2007). El Amparo Federal Argentino y la "Doble Instancia”. La Ley D, p. 925.

García Damborenea, R. (2000). Diccionario de falacias. Madrid, España: Biblioteca Nueva.

García Ramírez, S. (2011). El control judicial interno de convencionalidad. Revista IUS, 5, 123-159. Recuperado el 05 de marzo del 2020 de https://dialnet.unirioja.es/servlet/articulo?codigo $=6360863$

Ibarlucía, E. A. (2010). ¿Es una exigencia constitucional la doble instancia en el proceso civil?. La Ley D, p. 870 .

Kielmanovich, J. L. (2006). La doble instancia y la Convención Americana de Derechos Humanos. La Ley C, p. 964.

Laise, L. D. (2017). El poder de los conceptos: convenciones semánticas y objetividad referencial en la interpretación constitucional originalista. México D.F., México: Porrúa.

Monterisi, R. D. (2011). El derecho al recurso como garantía constitucional en el proceso civil. La Ley $B$, p. 767.

Nash Rojas, C. (2018). La doctrina del margen de apreciación y su nula recepción en la jurisprudencia de la Corte Interamericana de Derechos Humanos. Anuario Colombiano de Derecho Internacional, 11, 71-100. Recuperado el 20 de febrero del 2020 de https://revistas.urosario.edu.co/index.php/acdi/article/view/6539

Organización de los Estados Americanos. (1969). Conferencia Especializada Interamericana sobre Derechos humanos. Recuperado el 15 de febrero del 2020 de https://www.oas.org/es/cidh/mandato/Basicos/actas-conferencia-interamericana-DerechosHumanos-1969.pdf

Pasco Cosmópolis, M. (1994). El principio protector en el derecho procesal del trabajo. Derecho PUCP, 48, 149-169. Recuperado el 22 de febrero del 2020 de http://revistas.pucp.edu.pe/index.php/derechopucp/article/view/6718

Pinto, M. (1997). El principio pro homine. Criterios de hermenéutica y pautas para la regulación de los derechos humanos. En M. Pinto, M. Abregú \& C. Courtis (Eds.), La aplicación de los derechos humanos por los tribunales locales (pp. 163-172). Buenos Aires, Argentina: Ediciones del Puerto.

Toller, F. M. (2014). Metodología para tomar decisiones en litigios y procesos legislativos sobre derechos fundamentales. En Rivera, Julio César (h.), J. S. Elías, L. S. Grosman \& S. Legarre 
(Eds.), Tratado de Derechos Constitucionales (pp. 107-199). Buenos Aires, Argentina: Abeledo-Perrot.

Valenzuela Villalobos, W. (2013). Reflexiones sobre el derecho al recurso a partir de la sentencia "Mohamed vs. Argentina" de la Corte Interamericana de Derechos Humanos: cuestiones a tener en consideración sobre el sistema recursivo en el Proyecto de Código Procesal Civil. Estudios constitucionales, 11(2), 713-736.

\section{Jurisprudencia citada}

CSJN. (1946). “García, Julio L. c/ Nicora, Domingo”, Fallos 205:68.

CSJN. (1957). Sentencia del caso Scavino, Remo José c/ Vallanía, Francisco Fallos 238:71.

CSJN. (1959). Sentencia del caso Messen, Celia, y otros c/ Perona Barbouth S.R.L., Fallos 244:301.

CSJN. (1960). Sentencia del caso Arece, Dominga c/ Bellocchio Loustao, Eugenio A., Fallos 240:15.

CSJN. (1962). Sentencia del caso Laperne, Pedro Alfredo, Fallos 253:15.

CSJN. (1963). Sentencia del caso Mario Santiago Ischia vs. José Benjamin Wajsbekier, Fallos 256:440.

CSJN. (1995). Sentencia del caso Giroldi Horacio David y otro s/Recurso de Casación -Causa $n^{\circ} 32$, Fallos 318:514.

CSJN. (1996). Sentencia del caso Martins, Raúl Luis s/ defraudación por retención indebida - causa $\mathrm{N}^{\circ} 105$ - Fallos 319:699.

CSJN. (1997). Sentencia del caso Arce, Jorge Daniel s/ recurso de casación, Fallos 320:2145.

CSJN. (1999). Sentencia del caso Gorriaran Merlo, Enrique Haroldo y Sivori, Ana Maria s/ casación e inconstitucionalidad, Fallos 322:2488.

CSJN. (2001). Sentencia del caso Grano, Marcelo Alejandro s/ abuso deshonesto agravado por el vínculo en concurso real con coacción, Fallos 324:2554.

CSJN. (2004a). Sentencia del caso Vizzoti, Carlos c/ AMSA S.A. s/ Despido, Fallos 327:3677.

CSJN. (2004b). Sentencia del caso Aquino, Isacio c/ Cargo Servicios Industriales S.A. s/ accidentes ley 9688, Fallos 327:3753.

CSJN. (2007). Sentencia del caso Conductil S.A.C.I.F.I.A. c/ Music House Jujuy S.R.L. y otros s/Sumario, Fallos 330:1036.

CSJN. (2009). Sentencia del caso Pérez, Aníbal Raúl c/ Disco S.A, Fallos 332:2043.

CSJN. (2010). Sentencia del caso Ascua, Luis Ricardo c/ SOMISA s/ cobro de pesos, Fallos 333:1361.

CSJN. (2017). Sentencia del caso Ministerio de Relaciones Exteriores y Culto s/ informe sentencia dictada en el caso 'Fontevecchia y D'Amico vs. Argentina' por la Corte Interamericana de Derechos Humanos. Fallos 340:47.

Cámara Nacional de Apelaciones del Trabajo, Sala VII, de Argentina. (2016). Herrera, Ángel Gustavo c/ Prevención Art. S.A. s/ Accidente - Ley Especial.

Colombia. Corte Constitucional (2006). Sentencia C-355. Recuperado el 21 de febrero del 2020: https://www.corteconstitucional.gov.co/relatoria/2006/c-355-06.htm

Corte Interamericana de Derechos Humanos (Corte IDH). (1990). Opinión Consultiva No 11/90. Excepciones al agotamiento de los recursos internos (art. 46.1, 46.2.a y 46.2.b Convención Americana sobre Derechos Humanos). Recuperado el 14 de febrero del 2020 de http://www.corteidh.or.cr/docs/opiniones/seriea_11_esp.pdf

Corte IDH. (1998). Sentencia del caso "Panel Blanca" (Paniagua Morales y otros) vs. Guatemala. $\begin{array}{llllll}\text { Recuperado el } & 14 & \text { de } & \text { febrero } & \text { del } & 2020\end{array}$ http://www.corteidh.or.cr/docs/casos/articulos/seriec_37_esp.pdf 
Corte IDH. (2001a). Sentencia del caso "Tribunal Constitucional" (Aguirre Roca, Rey Ferry y Revoredo Marsano) vs. Perú. Recuperado el 14 de febrero del 2020 de http://www.corteidh.or.cr/docs/casos/articulos/Seriec_71_esp.pdf

Corte IDH. (2001b). Sentencia del caso Baena Ricardo y otros vs. Panamá. Recuperado el 14 de febrero del $2020 \mathrm{de}$ http://www.corteidh.or.cr/docs/casos/articulos/Seriec_72_esp.pdf

Corte IDH. (2001c). Sentencia del caso Ivcher Bronstein vs. Perú. Recuperado el 14 de febrero del 2020 de http://www.corteidh.or.cr/docs/casos/articulos/seriec_74_esp.pdf

Corte IDH. (2002). Sentencia del caso Hilaire, Constantine, Benjamin y otros vs Trinidad y Tobago. $\begin{array}{lllllll}\text { Recuperado } & \text { el } & 20 & \text { de } & \text { febrero } & \text { del }\end{array}$ https://www.corteidh.or.cr/docs/casos/articulos/Seriec_94_esp.pdf

Corte IDH. (2003). Opinión Consultiva N 18 "Condición jurídica y derechos de los migrantes indocumentados". Recuperado el 14 de febrero del 2020 de https://www.acnur.org/fileadmin/Documentos/BDL/2003/2351.pdf

Corte IDH. (2005). Sentencia del caso Yatama vs. Nicaragua. Recuperado el 20 de febrero del 2020 de http://www.corteidh.or.cr/docs/casos/articulos/seriec_127_esp.pdf

Corte IDH. (2006a). Sentencia del caso Ximenes Lopes vs. Brasil. Recuperado el 20 de febrero del $2020 \mathrm{de}$ http://www.corteidh.or.cr/docs/casos/articulos/Seriec_149_esp.pdf

Corte IDH. (2006b). Sentencia del caso Claude Reyes y otros vs. Chile. Recuperado el 20 de febrero de 2020 de http://www.corteidh.or.cr/docs/casos/articulos/seriec_151_esp.pdf

Corte IDH. (2007). Sentencia del caso Herrera Ulloa vs. Costa Rica. Recuperado el 21 de febrero del $2020 \mathrm{de}$ http://www.corteidh.or.cr/docs/casos/articulos/seriec_107_esp.pdf

Corte IDH. (2010). Sentencia del caso Vélez Loor vs. Panamá. Recuperado el 20 de febrero del 2020 de http://www.corteidh.or.cr/docs/casos/articulos/seriec_218_esp2.pdf

Corte IDH. (2011). Sentencia del caso Barbani Duarte y otros vs Uruguay. Recuperado el 20 de febrero del 2020 de http://www.corteidh.or.cr/docs/casos/articulos/seriec_243_esp.doc

Corte IDH. (2017a). Sentencia del caso Lagos del Campo vs. Perú. Recuperado el 20 de febrero de $2020 \mathrm{de}$ http://www.corteidh.or.cr/docs/casos/articulos/seriec_340_esp.pdf

Corte IDH. (2017b). Sentencia del caso Trabajadores Cesados de Petroperú vs. Perú. Recuperado el 20 de febrero de $2020 \mathrm{de}$ http://www.corteidh.or.cr/docs/casos/articulos/seriec_344_esp.pdf

SCBA. (1994). Sentencia del caso Vittar, Eduardo Calim contra Todo Quebracho S.A. Cobro de australes, Ac. 50.993. Recuperado el 20 de febrero del 2020 de https://juba.scba.gov.ar/VerTextoCompleto.aspx?idFallo=111491

SCBA. (2000). Sentencia del caso Sampayo, Marcela A. contra Editora carpetas de derecho S.A. Despido. Rec. de queja, Ac. 78.703. Recuperado el 20 de febrero del 2020 de https://juba.scba.gov.ar/VerTextoCompleto.aspx?idFallo=113596

SCBA. (2006). Sentencia del caso Pellejero, Carlos Daniel y otros contra Transp. 9 de Julio S.R.L. y otros. Dif. de haberes, indem., L. 106.055. Recuperado el 20 de febrero del 2020 de https://juba.scba.gov.ar/VerTextoCompleto.aspx?idFallo=88608

SCBA. (2011). Sentencia del caso R. E. M. contra Colegio de Kinesiólogos de la Provincia de Buenos Aires s/ pretensión anulatoria, LP.A 69692. Recuperado el 20 de febrero del 2020 de https://juba.scba.gov.ar/VerTextoCompleto.aspx?idFallo=73354

SCBA. (2015). Sentencia del caso Lozano, J. C. c/ Lavagnino Metalmecánica y otro s/ Despido, L. 116.822. Recuperado el 20 de febrero del 2020 de http://www.scba.gov.ar/includes/descarga.asp?id=32211\&n=Ver\%20Sentencia \%20(111682 2).pdf 
SCBA. (2019a). Sentencia del caso Gigena, Oscar Aníbal contra Néstor F. Diez S.A. y otro/a. Daños y perjuicios, L. 120.951. Recuperado el 20 de febrero del 2020 de https://juba.scba.gov.ar/VerTextoCompleto.aspx?idFallo=171294

SCBA. (2019b). Sentencia del caso Centauro S.A. c/ Ministerio de Trabajo de la Prov. de Bs. As. s/ Recurso de Queja", L-120947. Recuperado el 20 de febrero del 2020 de https://juba.scba.gov.ar/VerTextoCompleto.aspx?idFallo=172095

\section{Resoluciones}

SCBA (2019). Resolución 3199 del 04 de diciembre de 2019. Recuperado el 16 de agosto de 2020 de http://www.scba.gov.ar/includes/descarga.asp?id=44540\&n=Res\%20SCJ\%203199-19.pdf

\section{Financiación}

Este artículo se inserta en el proyecto de investigación titulado: "El concepto de Dignidad Humana según la Corte Interamericana de Derechos Humanos. Análisis de los casos contenciosos y de las opiniones consultivas" (Código PICTO-2017-0032), financiado por la Agencia Nacional de Promoción Científica y Tecnológica (Argentina).

\section{Agradecimientos}

Los autores reconocen y agradecen a Gustavo Manzó por la discusión de algunas de las ideas que han modelado a la estructura de este trabajo.

\section{Contribución autoral}

a) Concepción y diseño del trabajo; b) Adquisición de datos; c) Análisis e interpretación de datos; d) Redacción del manuscrito; e) revisión crítica del manuscrito.

L. D. L. ha contribuido en a, c, d.; J. S. B.A ha contribuido en b, e.

\section{Editor científico responsable}

Dr. Pablo Rodríguez Almada 